
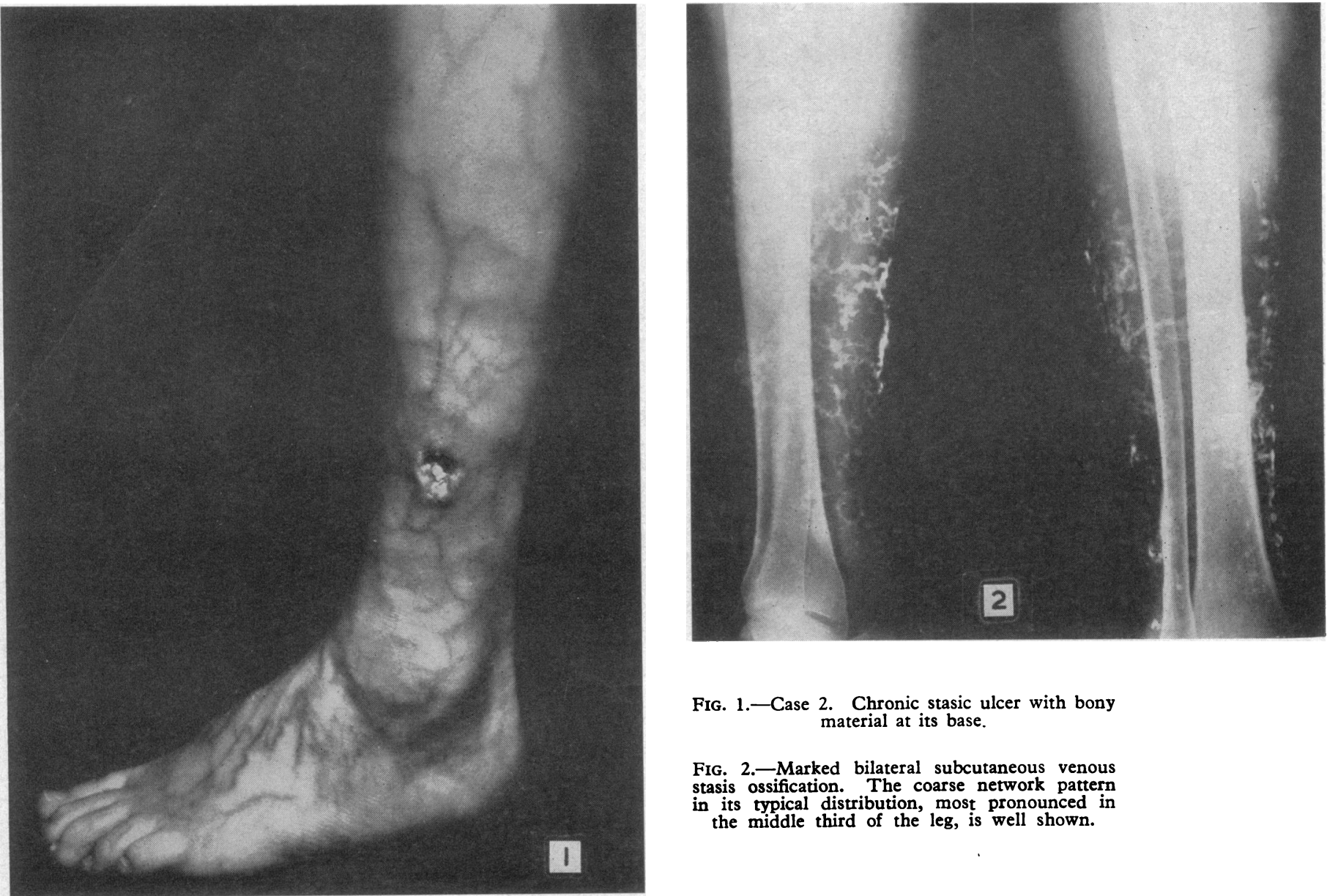

FIG. 1.-Case 2. Chronic stasic ulcer with bony material at its base.

Fig. 2.-Marked bilateral subcutaneous venous stasis ossification. The coarse network pattern in its typical distribution, most pronounced in in its typical distribution, most pronounced
the middle third of the leg, is well shown.

FIGs. $3 a$ and $3 b$.-Lymphangiogram showing only a single lymphatic draining the greater saphenous system, dermal backflow, and lymphatic obstruction.
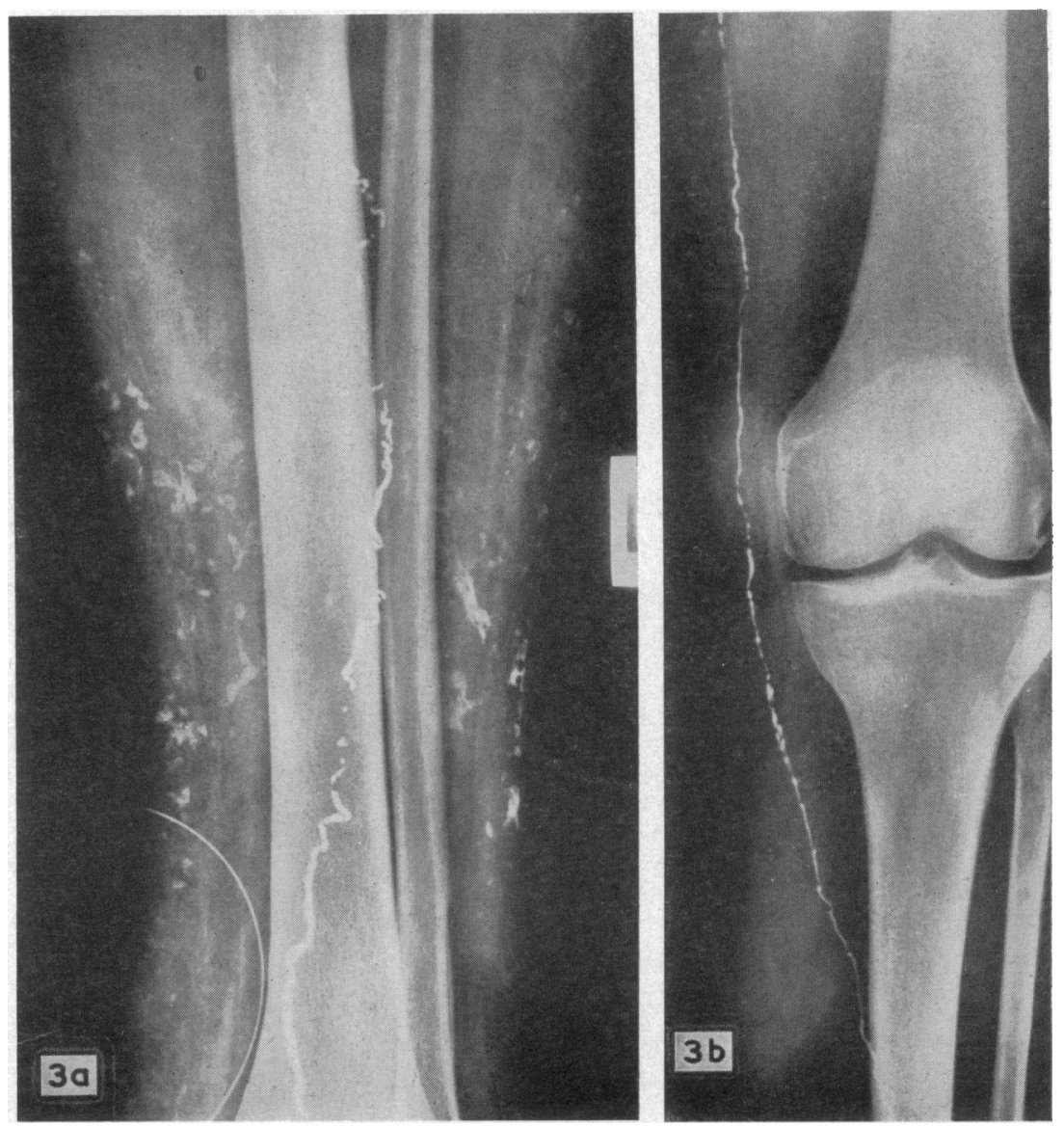


\title{
Subcutaneous Ossification of the Legs in Chronic Venous Stasis
}

\author{
I. SARKANY,* M.R.C.P. ; L. KREEL, † M.R.C.P., F.P.R.
}

[With Special Plate]

Brit. med. F., 1966, 2, 27-28

Subcutaneous ossification of the legs associated with chronic venous insufficiency is not a well-recognized entity. However, other types of radio-opacities are well recognized-for example, arterial calcification, phleboliths, ligamentous calcification in Pellegrini-Stieda disease, and cysticercosis. Venous stasis ossification in the lower limbs may be seen with a nonhealing ulcer or may occur in the absence of ulceration as an incidental clinical or radiological finding. The appearances of this not uncommon condition are specific and their recognition should save unnecessary metabolic investigations-for example, scium calcium and phosphorus estimations. The condition may have a bearing on treatment of the ulcer.

This is a report of eight patients (see Table) with subcutaneous ossification of the legs. The following two detailed case reports illustrate some of the various clinical features and behaviour of this disorder.

Case 2.-A 58-year-old man was seen in 1963 with two ulcers above the left ankle. There was an ulcer $\frac{1}{2}$ in. $(1.3 \mathrm{~cm}$.) in diameter above the medial malleolus, and another 2 in. $(5 \mathrm{~cm}$.) in diameter above the lateral malleolus (Special Plate, Fig. 1). He had fractured the left patella in 1945 and the left femur in 1947. One of his sisters had varicose veins. Examination revealed marked varicose veins of both legs and ulcers with ossified material in their bases; stony-hard plaques were felt over both shins and calves. Detailed blood investigations were negative, and the serum calcium was $9.8 \mathrm{mg} . / 100 \mathrm{ml}$. and the serum phosphorus $3.2 \mathrm{mg} . / 100 \mathrm{ml}$. Repeated examinations of skin scrapings and nail clippings were negative for fungus, and a full skeletal survey revealed no evidence of abnormality except in the legs. Extensive ossification was nnted in the subcutaneous tissues of both legs. Histological examination showed fragments of necrotic adipose tissue partially covered by fibrous tissue and purulent exudate undergoing calcification around the edges. In several areas the appearances were those of osteoid tissue. The ulcers healed with bed rest, daily dressings, and supportive elastic bandages.

Case 3.-A woman aged 71 had suffered from ulceration of the left leg for six years. Six months before admission in 1962 she had been in hospital for six weeks for the ulceration, but no healing of the ulcers took place. Examination showed ulceration on the medial and lateral aspects of the left leg. In the floor of the ulcers plaques of bony material could be seen, and extensive subcutaneous thickening was palpable over both legs below the knee. The area around the ulcers showed evidence of dermatitis. Radio-

* Consultant Dermatologist, Royal Free Hospital, London. t Consultant Radiologist, Royal Free Hospital, London. graphs demonstrated an extensive lacework of subcutaneous ossification. The serum calcium ${ }_{2}$ phosphorus, and phosphatase levels were normal. Conservative treatment of the ulcers and skin failed to effect improvement. All accessible plaques of ossification were therefore surgically removed and skin-grafting was carried out. There was a $50 \%$ take, and, except for one or two small unhealed areas, an excellent result was achieved within five weeks of the operation.

\section{Discussion}

Clinical manifestations of chronic venous insufficiency are chronic dermatitis, cellulitis, atrophy of skin and subcutaneous tissue, induration, and brown discoloration. Later sequelae include recurrent ulceration and subcutaneous ossification (Lippmann and Goldin, 1960). These authors have described a series of 600 patients with chronic venous insufficiency of the legs and found that $60(10 \%)$ had subcutaneous ossification. This is said to have occurred exclusively in postmenopausal females with chronic venous insufficiency and fungus infection of the feet. Fisher (1961) reported the case of a patient who conformed to these criteria - that is, was a postmenopausal woman with chronic stasis and a fungus infection of the feet.

In our series of eight patients with subcutaneous ossification one (Case 2) was a male. He had no associated dermatomycosis of the feet. Similarly, several of the female patients in whom fungus infection was looked for carefully, both clinically and mycologically, showed no evidence of this.

It is therefore likely that the presence of a superficial fungus infection is an incidental finding which is much more commonly seen in those parts of the United States where the above two reports originated. Subcutaneous ossification in our series affected both middle-aged and elderly females and males, and the only constant association was long-standing venous stasis with or without ulceration.

The exact incidence of this condition is not known. The eight cases reported here were seen over a four-year period. Whereas Lippmann and Goldin (1960) found that $10 \%$ of all cases of chronic stasic ulceration were associated with subcutaneous ossification, Stevens (Personal communication, 1965) at this hospital failed to find a single case of this condition in a series of 25 consecutive patients with severe chronic ulceration of the legs. Nine of his patients showed

Summary of Clinical and Radiological Data in 8 Patients with Subcutaneous Ossification of Legs

\begin{tabular}{|c|c|c|c|c|c|c|c|}
\hline $\begin{array}{l}\text { Case } \\
\text { No. }\end{array}$ & Age & Sex & $\begin{array}{l}\text { Evidence of } \\
\text { Stasis }\end{array}$ & $\begin{array}{l}\text { Presence of } \\
\text { Fungus }\end{array}$ & $\begin{array}{l}\text { Response } \\
\text { to Treatment }\end{array}$ & $\begin{array}{l}\text { Radiological } \\
\text { Changes }\end{array}$ & Investigations \\
\hline 1 & 70 & $\mathbf{F}$ & $\begin{array}{l}\text { Severe varicose veins. Stasic } \\
\text { pigmentation }\end{array}$ & Negative & Symptomless & Severe & $\begin{array}{l}\text { Normal serum calcium and } \\
\text { phosphorus. Biopsy of } \\
\text { plaque: bone }\end{array}$ \\
\hline 2 & 58 & $\mathbf{M}$ & $\begin{array}{l}\text { Chronic stasic ulcers. Severe } \\
\text { varicose veins }\end{array}$ & $"$ & $\begin{array}{l}\text { Healing of ulcers with bed rest } \\
\text { and supportive therapy }\end{array}$ & Extensive & $\begin{array}{l}\text { plaque: bone } \\
\text { Normal biochemistry. } \\
\text { Biopsy of plaque: }\end{array}$ \\
\hline 3 & 71 & $\boldsymbol{F}$ & $\begin{array}{l}\text { Ulcers. Stasis dermatitis } \\
\text { and varicose veins }\end{array}$ & $?$ & $\begin{array}{l}\text { Failure of conservative therapy. } \\
\text { Successfully grafted }\end{array}$ & Moderate & Normal biochemistry \\
\hline 4 & 85 & $\mathbf{F}$ & $\begin{array}{l}\text { Ulceration. Poor peripheral } \\
\text { circulation }\end{array}$ & $?$ & Died of intercurrent illness & 川 & " , \\
\hline 5 & 72 & F & $\begin{array}{l}\text { Varicose veins. Varicose } \\
\text { eczema. Poor peripheral } \\
\text { circulation }\end{array}$ & $?$ & Poor response & ? Moderate & Not done \\
\hline 6 & 61 & $\mathbf{F}$ & $\begin{array}{l}\text { Swelling of legs. Cellulitis. } \\
\text { Lymphatic hypoplasia }\end{array}$ & Negative & Supportive therapy & Moderate. Also had & " $"$ \\
\hline 7 & 82 & $\mathbf{F}$ & $\begin{array}{l}\text { Marked varicose veins. } \\
\text { Healed stasic ulcer }\end{array}$ & $?$ & " & Slight lymphangiogram & Normal biochemistry \\
\hline 8 & & & Only radiographs available w & ich show typi & cal pattern of ossification of mo & rate degree & \\
\hline
\end{tabular}


minor radio-opacities ranging from phleboliths and arterial calcification to calcified periosteal reactions.

The presence of bone in the base of the ulcer may be a cause for non-healing. In two of our cases in which loose bone was removed more rapid healing seemed to occur on conservative treatment. However, in other cases, where subcutaneous bone was not removed from the ulcer or adjacent areas, healing took place with conservative treatment, surgical measures not being necessary. It is therefore difficult to assess the effect of ossification on healing of a chronic ulcer. The bone may be the cause or the effect of non-healing of the ulcer. The formation of new bone may conceivably be part and parcel of the long-term tissue changes associated with prolonged venous stasis.

The appearances of subcutaneous ossification are pathognomonic (Moberg, 1939; Gray, 1959). This ossification is confined to the subcutaneous layer and produces a coarse network or opacities of bone density in the leg below the knee and above the ankle (Special Plate, Fig. 2). When seen in profile it produces a straight edge, which can be seen to impinge on the subdermal layers. There are definite variations in density within this coarse network, which tends to encircle the leg and occurs most markedly in its middle third. This network of subcutaneous ossification may vary in extent from a small area to relatively widespread involvement. It is easily distinguished from phleboliths, arterial calcification, or periosteal reactions. Though the three latter types of change are often found with varicose veins and may occur with the ossification network pattern, they can easily be recognized. Other radiographic opacities which occur in soft tissues, such as those seen in cysticercosis, guinea-worms, and calcification of the Ehlers-Danlos syndrome, are also quite unlike venous stasis ossification.

The exact mechanism of new bone formation or calcification in soft tissues in unknown, and nothing is known of the cause of ossification in venous stasis. Calcium, phosphorus, and phosphatase levels in the serum and urine are not related to the type of calcification or ossification seen in, for example, venous stasis, non-parasitic cysts of the spleen, thyroid adenomas, or traumatic myositis ossification. In these conditions such investigations are therefore regarded as superfluous. Similarly, it has now been shown in many cases, as well as in the cases described, that these biochemical investi- gations are invariably negative and can therefore be omitted. The radiological appearance, as described above, is unmistakable and diagnostic of this condition.

The histological changes in and around stasis ulcers have been well documented (Moyer and Butcher, 1955). They include arteriolar and venular luminal obliteration, perineural inflammation, hypertrophy and fibrosis of the dermis, and epidermal atrophy. There may also be lymphatic obliteration, though this is often overlooked. One of the patients in this series presented herself with swelling of the feet and was referred for lymphangiography. She showed " a dermal backflow pattern" with the initial patent violet-blue injection. This is characteristically present in lymphatic oedema. Subsequently, blocked lymphatics with lymphangiographic dermal backflow and only a single small lymphatic trunk in the greater saphenous drainage area were demonstrated (Special Plate, Fig. 3), in addition to her subcutaneous ossification.

\section{Summary}

Eight cases are reported of subcutaneous ossification of the legs in association with chronic venous stasis.

The clinical and radiographic features make a definitive diagnosis possible without recourse to biochemical investigations.

Venous stasis subcutaneous ossification may occur in males as well as in post-menopausal females and has been seen in the absence of fungal infection, contrary to previous reports. Peripheral oedema and lymphatic occlusion, on the other hand, is an occasional associated feature.

We are grateful to Mr. George Qvist, Senior Surgeon at the Royal Free Hospital, for permission to include Case 2. We are also indebted by Mr. Stanley Lee and Dr. B. Strickland, of the Westminster Hospital, for allowing us to include Case 3 . We thank Mr. R. R. Phillips, of the Photographic Department of the Royal Free Hospital, for help with the illustrations.

\section{REFERENCES}

Fisher, B. K. (1961). 7. Amer. med. Ass., 176, 376.

Gray, E. D. (1959). A Text-book of X-ray Diagnosis, 3rd ed., edited by S. C. Shanks and P. Kerley, vol. IV, p. 658. Lewis, London

Lippmann, H. I. and Goldin, R. R. (1960). Radiology, 74, 279

Lippmann, H. (1939). Acta radiol. (Stockh.), 20, 150.

Moyer, C. A., and Butcher, H. R. (1955). Ann. Surg., 141, 577.

\section{Preliminary Communications}

\section{Oxygenation of Cats by Hydrogen Peroxide during Temporary Ventilatory Arrest}

Brit. med. F., 1966, 2, 28-30

Cyanosis in patients with congenital heart disease is due to a shunt of desaturated blood from the right side of the heart into the arterial circulation, and this mechanism may also contribute to hypoxaemia in many forms of pulmonary disease. This shunt blood is not exposed to the ventilating surfaces of the lung, and its oxygen content cannot therefore be affected either by increasing the alveolar ventilation or by increasing the partial pressure of oxygen in the lungs. The only improvement in oxygenation to be expected by these measures will be from oxygen dissolved in the plasma in that portion of the cardiac output that takes no part in the shunt. A study of alternative methods of oxygenation has led to the present investigation of the use of hydrogen peroxide, infused intra-arterially, to provide an auxiliary means of oxygenation.
If hydrogen peroxide was infused slowly into the aorta during ventilatory arrest, it was anticipated that in the presence of catalase this would release micro-bubbles of oxygen which would accumulate in the lower part of the body. A high partial pressure of oxygen in these tissues would then occur. presaturated arterial blood in this region would become saturated with oxygen as it passed into the venous system. In this way the blood returning to the heart in the inferior vena cava would be fully saturated with oxygen. The oxygen tension in the inferior vena cava should be capable of being controlled by varying the rate of the infusion and thus kept below that partial pressure at which spontaneous bubble formation occurred. When the infusion was stopped any bubbles trapped in the capillary bed of the hind limbs would dissolve spontaneously as the oxygen tension in the tissues fell. To test the validity of this hypothesis a preliminary experiment was carried out with 14 cats. They were anaesthetized and then subjected to ventilatory arrest to produce an extreme degree of hypoxaemia.

It has proved possible in these circumstances to supply suffcient oxygen by means of hydrogen peroxide to maintain life 